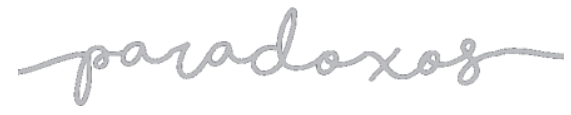

Covid-19 em revistas no Instagram: uma análise de conteúdo relacionada às orientações do UNICEF e da OMS

LEÃO, SERAFIM, NUNES, PEREIRA, 2020

\title{
Covid-19 em revistas no Instagram: uma análise de conteúdo relacionada às orientações do UNICEF e da OMS
}

\author{
Covid-19 in magazines on Instagram: a content analysis related to \\ UNICEF and WHO guidelines
}

\section{Covid-19 en revistas de Instagram: um análisis de contenido relacionado com las directrices de UNICEF y la OMS}

\author{
Callenciane Ferreira Leão \\ Universidade Federal do Rio Grande do Sul - UFRGS \\ Endereço currículo Plataforma Lattes: http://lattes.cnpq.br/3868894284080318 \\ E-mail: callen.ce@gmail.com \\ Luciana Santos Serafim \\ Universidade de Fortaleza - UNIFOR \\ E-mail: $\underline{\text { lua.sserafim@gmail.com }}$ \\ Dháfine Mazza Nunes \\ Universidade Federal do Ceará - UFC \\ Endereço currículo Plataforma Lattes: http://lattes.cnpq.br/3134202323753435 \\ E-mail: dhafine@gmail.com \\ Germana da Cruz Pereira \\ ORCID: https://orcid.org/0000-0001-7721-2077 \\ Endereço currículo Plataforma Lattes: http://lattes.cnpq.br/0042519787694969 \\ E-mail: germanadacruz@hotmail.com
}

\begin{abstract}
Resumo: No presente artigo analisamos como as revistas brasileiras Crescer e Pais \& Filhos, cuja temática principal é família, abordam em seus perfis na rede social Instagram a pandemia Covid-19 no período de 12 de março a 11 de abril de 2020. Para tanto, tomamos como base teórica as discussões sobre comunicação e teoria do agendamento de Maxwell McCombs e DonaldShaw (1970) e redes sociais de Castells (2002) e Recuero (2009). Com isso, identificamos temas abordados com recorrência no período analisado, categorizando as postagens conforme os assuntos e analisando seu alinhamento com as orientações do UNICEF e OMS sobre Covid-19, família e crianças durante o isolamento social. Ao final, observamos o agendamento da pandemia nas publicações dos perfis, bem como uma aproximação às diretrizes dos órgãos internacionais.
\end{abstract}

Palavras-chave: Revistas. Instagram. Redes Sociais. Covid-19. Família. 
Abstract: In this article we analyze how Brazilian magazines Cresce and Pais \& Filhos, whose main theme is family, approach in their Instagram social network profile the Covid-19 pandemic in the period from March 12 to April 11, 2020. Therefore, we took as theoretical basis discussions about Maxwell McCombs and DonaldShaw's communication and agenda-setting (1970), and Castells's (2002) and Recuero's (2009) social network. With that, we identified themes that were recurrently addressed in the analyzed period, categorizing posts by subject and analyzing their alignment with UNICEF and WHO guidelines on Covid-19, family and children during social isolation. In the end, we observed the scheduling of the pandemic in the profile publications, as well as an approximation to the guidelines of international bodies.

Keywords: Magazines. Instagram. Social Network. Covid-19. Family.

Resumen: En este artículo, analizamos cómo las revistas brasileñas Crescer y Pais \& Filhos, cuyo tema principal es la familia, abordan la pandemia de Covid-19 en sus perfiles en la red social de Instagram del 12 de marzo al 11 de abril de 2020. Por lo tanto, tomamos como base teórica las discusiones sobre la teoría de la comunicación y la programación (agenda setting) de Maxwell McCombs y DonaldShaw (1970) y las redes sociales de Castells (2002) y Recuero (2009). Como resultado, identificamos problemas que se abordaron de forma recurrente durante el período del informe, clasificando las publicaciones por tema y analizando su alineación con las directrices de UNICEF y la OMS sobre Covid-19, la familia y los niños durante el aislamiento social. Al final, observamos la programación de la pandemia en las publicaciones de los perfiles, así como un enfoque de las directrices de las organizaciones internacionales.

Palabras clave: Revistas. Instagram. Redes Sociales. Covid-19. Familia.

\section{Introdução}

A disseminação mundial do novo Coronavírus no início do ano de 2020, causador da Covid-19, marcou a cobertura de vários veículos jornalísticos, tanto na concentração de pautas relacionadas à doença quanto na forma de executá-las, com adequações de processos de trabalho. Nesse cenário, o jornalismo reacende em importância por seus métodos, formatos e acuracidade no trato com a informação, entre outras características, a exemplo de desdobramentos em redes sociais, onde também é possível exercer o papel de informar a sociedade. 
Questões relacionadas à saúde pública em redes sociais, por exemplo, inspiraram estudos como um sobre a epidemia do vírus Ebola na África ocidental, feito por Seltzer et al. (2015), com foco no compartilhamento de imagens nas redes sociais Instagram e Flickr, a partir da hashtag \#ebola. Outro estudo foi sobre rumores sobre dengue, chikungunya, zika, Aedes aegypti e microcefalia quanto a número de casos suspeitos, confirmados ou descartados pela Vigilância Epidemiológica do Estado de Santa Catarina, feito por Klein, Neto e Tezza (2007), através do monitoramento de redes sociais como Facebook, Twitter, Instagram, Flickr, Youtube e blogs. A Covid-19, por sua vez, foi tema de uma análise na China, enquanto a doença ainda era considerada apenas uma epidemia. Com técnica de mineração de dados em textos na rede de blogs Sina, Zhao et al. (2020) observaram as palavras mais frequentes em referência à Covid-19, com análise de sentimentos relacionados, para identificar a opinião do público a respeito do tema.

No presente artigo, nos concentramos em analisar como as páginas na rede social Instagram dos perfis das revistas brasileiras Crescer e Pais \& Filhos, cujas reportagens, notícias e colunas abordam temas ligados à família, apresentaram os conteúdos relacionados à Covid-19, que foi declarada pela Organização Mundial de Saúde (OMS) como pandemia em 11 de março de $2020^{1}$. No Brasil, um dia após essa declaração da OMS, foi publicada a Portaria 356, do Ministério da Saúde, tratando das ações de combate à pandemia ${ }^{2}$. Então, cada Estado brasileiro foi tomando medidas específicas ao longo das semanas seguintes através de decretos oficiais ${ }^{3}$. A pandemia, que era já era um assunto debatido em veículos internacionais e nacionais ${ }^{4}$, ganhava mais destaque no Brasil.

1 A Covid-19 configurava uma pandemia dada sua gravidade. Disponível em: https://g1.globo.com/bemestar/coronavirus/noticia/2020/03/11/oms-declara-pandemia-de-coronavirus.ghtml. Acesso em: 16 de mai. de 2020.

${ }^{2}$ É válido ressaltar que o isolamento era uma medida para evitar a "propagação da infecção e transmissão local", através da separação de "pessoas sintomáticas ou assintomáticas, em investigação clínica e laboratorial", enquanto a quarentena deveria ser determinada por "ato administrativo formal" e divulgada por " meios de comunicação" a fim de evitar o colapso no sistema de saúde. Disponível em: http://www.in.gov.br/en/web/dou/-/portaria-n-356-de11-de-marco-de-2020-247538346. Acesso em 16 de mai. de 2020.

${ }^{3}$ Os cinco Estados inicialmente com maior números de casos de Covid-19 adotaram em diferentes dias do mês de março algumas medidas através de decretos oficiais: São Paulo (com quarentena através do Decreto 64.881, de 22 de março), Rio de Janeiro (com quarentena e isolamento pela Lei 8.770 de 23 de março), Distrito Federal (com medidas adotadas pelo Decreto 40.550, de 23 de março, depois revogado pelo Decreto 40583, de 1 de abril de 2020), Ceará (com situação de emergência e medidas de enfrentamento da infecção humana pelo novo Coronavírus, no Decreto 33.519, de 19 de março, Minas Gerais (com medidas iniciais pelo Decreto 47.886, de 15 de março). Disponível em: https://agenciabrasil.ebc.com.br/saude/noticia/2020-04/covid-19-veja-como-cada-estadodetermina-o-distanciamento-social. Acesso em: 16 de mai. de 2020.

4 O Boletim Epidemiológico 5 (14 de março) do Ministério da Saúde colocou "a recomendação de isolamento domiciliar de pessoas com sintomas (febre + sintomas respiratórios) vindas do exterior”. Disponível em: DOI: http://doi.org/10.14393/par-v5n1-2020-55104 - Paradoxos, Uberlândia, v. 5, n. 1, p. 20-35, jan./jun. 2020 


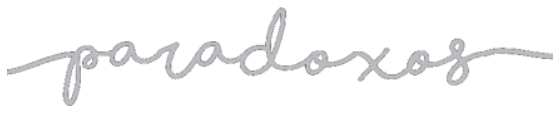

Covid-19 em revistas no Instagram: uma análise de conteúdo relacionada às orientações do UNICEF e da OMS

LEÃO, SERAFIM, NUNES, PEREIRA, 2020

Dessa forma, acompanhamos as postagens dos perfis oficiais @ revistacrescer e @ paisefilhosoficial a partir do dia 12 de março de 2020, uma vez que já estava estabelecida oficialmente a condição de pandemia e havia uma portaria nacional sobre o assunto, até o dia 11 de abril do mesmo ano, configurando o primeiro mês de adaptação no país, embora se saiba que após esse período de tempo a Covid-19 continuou em evidência nos meios de comunicação e redes sociais.

As revistas Crescer e Pais \& Filhos não são revistas científicas, mas tratam de matérias de interesse geral, com linguagem acessível para que pais, mães e cuidadores possam se aproximar de temas relevantes sobre maternidade, paternidade e cuidados com crianças, incluindo questões de saúde pública, como o caso da Covid-19. Na rede social Instagram, as revistas têm a oportunidade de não apenas convidar por link para leitura de matérias aprofundadas no site, como publicar vídeos de colunistas, divulgar notícias e serviços de utilidade pública, lançando campanhas de engajamento para os leitores, entre outros tipos de postagens. No período em que foram analisados, os perfis das revistas @ revistacrescer e @ paisefilhosoficial agregavam, respectivamente, cerca de 817 mil e 415 mil seguidores no Instagram, sinalizando que os perfis se dirigem a públicos grandes.

Para este estudo, portanto, foram priorizadas postagens desses perfis relacionadas à Covid-19, com foco nas de abordagem informativa e identificando aspectos dos temas que caracterizaram o agendamento desses conteúdos, conforme critérios mais detalhados na análise e possíveis relações de aproximação às orientações do Fundo Das Nações Unidas Para a Infância (UNICEF) e a Organização Mundial de Saúde (OMS), responsáveis por informar medidas de combate esse problema de saúde pública. Tendo em vista os objetivos apresentados, esta investigação toma como base a Teoria do Agendamento, ou Agenda Setting, de Maxwell McCombs e DonaldShaw (1970), e redes sociais de Castells (2002) e Recuero (2009), além de desenvolver seu percurso metodológico composto por seleção e categorização dos dados, descrição e análise.

https://www.saude.gov.br/noticias/agencia-saude/46542-atualizacao-do-boletim-epidemiologico-covid-19. Acesso em: 16 de mai. de 2020. 


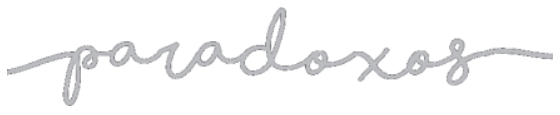

Covid-19 em revistas no Instagram: uma análise de conteúdo relacionada às orientações do UNICEF e da OMS

LEÃO, SERAFIM, NUNES, PEREIRA, 2020

\section{As revistas no Instagram}

De maneira geral, as revistas se propõem a inspirar os leitores não apenas pelo conteúdo, mas também pela forma. Essa característica faz parte da essência, por exemplo, das revistas jornalísticas sobre saúde, esporte, educação, arquitetura, entre outros temas. Assim, a relação de proximidade que se tenta estabelecer com o público considera esses interesses específicos, incluindo o modo de viver e de se comunicar do público (LEÃO, 2015). Ao fazer essa abordagem com foco nos interesses do público, as revistas tendem a mexer com os sentidos e as emoções através de recursos discursivos como textos e gráficos (BENETTI, 2013). Além disso, buscam aprofundar os temas (OLIVEIRA, 2011) ao explorar novos ângulos do assunto e criar oportunidades para ir além da notícia (SCALZO, 2011). No ambiente digital, algumas características do meio impresso podem ainda ecoar e se sobressair como o papel relevante do design (PAULINO, 2013; FRANCHI, 2013; SCALZO, 2011) e o aprofundamento do conteúdo (OLIVEIRA, 2011; BENETTI, 2013). A periodicidade da publicação também pode ser destacada (VOGEL, 2013; DOURADO, 2013), mas em se tratando de ambiente digital, como uma rede social, a frequência pode ter uma regularidade mais dinâmica.

As revistas Crescer e Pais \& Filhos, escolhidas para a análise, possuem versão no ambiente digital, com website, além das versões impressas, e perfis oficiais em redes sociais mediadas pelo computador (RECUERO, 2009), de forma a aproximar-se do leitor e captá-lo para o site. Isso indica a mudança tanto de suporte quanto de formato de construção e propagação de conteúdo. Tal adaptação pode ser observada nos perfis das revistas no Instagram, compreendendo, como pontua Recuero (2009, p. 54), que o capital social influencia a compreensão das relações sociais e suas conexões, assim como a produção de conteúdo. É justamente o conteúdo que possibilita conexões entre os atores nas redes sociais que nos interessa nesta investigação, visto que as redes sociais representam novos espaços discursivos e faz-se necessário analisar de que maneira "esses espaços podem desvelar formas de compreender a circulação e a legitimação dos discursos" (RECUERO, 2014, p.290).

A rede social Instagram, surgida em 2010 com o propósito inicial de compartilhamento de imagens pessoais, vem sendo modificada, agregando possibilidades para usuários individuais e empresas, como postagens curtas na linha dos Stories ou mais 


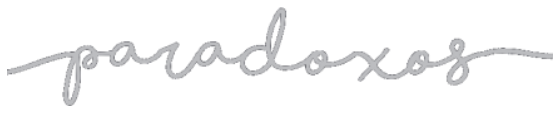

Covid-19 em revistas no Instagram: uma análise de conteúdo relacionada às orientações do UNICEF e da OMS

LEÃO, SERAFIM, NUNES, PEREIRA, 2020

longas, como no IGTV, com vídeos gravados ou transmissões ao vivo. Dessa forma, observamos a ampliação da sociedade em rede que, como esclarece Castells (2006, p.20), trata-se de uma "estrutura social baseada em redes operadas por tecnologias de comunicação e informação fundamentadas na microelectrónica e em redes digitais de computadores que geram, processam e distribuem informação", obtida pelo cruzamento de dados nos pontos de interseções (nodos) das redes.

O cruzamento de dados dos usuários permite que perfis, sites e produtos sejam sugeridos com base em suas buscas e conversas na Internet, o que pode direcionar a compreensão sobre determinado conteúdo ou necessidade de consumo. Apesar dos conteúdos serem sugeridos de acordo com as características pessoais, os indivíduos são "receptores coletivos de informação"(CASTELLS, 2006, p.23), que irão consumí-las e propagá-las por suas atitudes e seus discursos, o que justifica a necessidade de analisar o alinhamento, ou não, de postagens sobre a Covid-19 e o isolamento social com crianças nas redes sociais com orientações de instituições internacionais responsáveis por informar sobre a pandemia, bem como a relação com a teoria do agendamento (Agenda Setting).

\section{Orientações durante a pandemia}

O Fundo Das Nações Unidas Para a Infância (UNICEF) atua como uma das instituições responsáveis por informar sobre a Covid-19, em parceria com a Organização Mundial da Saúde (OMS) e departamentos governamentais. Atento aos reflexos e riscos de contaminação entre gestantes, idosos, famílias e crianças, o UNICEF elaborou listagem de dicas, artigos e guia sobre a doença e cuidados em geral.

O guia Key Messages and Actions for COVID-19 Prevention and Control in Schools - March, 2020 (UNICEF, OMS \& FIRC, 2020), por exemplo, contém orientações para pais, educadores e a comunidade em geral na atenção com as crianças no cenário da pandemia. No capítulo específico voltado para pais e cuidadores, recomenda-se que haja atenção a aspectos como: estar atento a notícias atualizadas sobre a situação da doença, seguir orientações de saúde pública e auxiliar no modo como as crianças lidam com os estresses desse contexto (UNICEF, OMS \& FIRC, 2020). A importância do uso de fontes seguras e oficiais de informação para combater fake news 


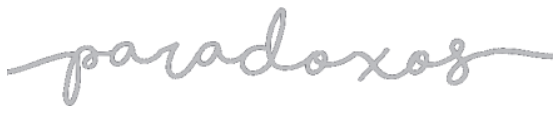

Covid-19 em revistas no Instagram: uma análise de conteúdo relacionada às orientações do UNICEF e da OMS

LEÃO, SERAFIM, NUNES, PEREIRA, 2020

é uma das medidas defendidas pelo UNICEF (2020), que também explica sobre a doença ter sido inicialmente identificada em Wuhan, China, onde foi nomeada "Doença Coronavírus 2019 (COVID-19)", relacionada à síndrome respiratória severa associada aos sintomas de um resfriado (UNICEF, 2020).

O cuidado na forma de abordar assuntos com as crianças também é recomendando pelo UNICEF (2020). Pais e cuidadores devem ser honestos, não necessariamente as deixando alheias à seriedade do momento, mas com diálogos mais cuidadosos. Em uma listagem de passos práticos para os pais oferecerem apoio às crianças durante o período de surto da Covid-19, o UNICEF (2020), com auxílio da psicóloga Dra. Lisa Damour, destaca que, diante da ansiedade e das incertezas inerentes ao momento de pandemia, seria adequado: 1) manter a calma e ser proativo, estabelecendo empatia e valorizando o ato de afastamento social como forma de proteger outras pessoas; 2) manter uma rotina, com estruturas de tempo no ambiente doméstico e variedade de atividades; 3) permitir que os filhos sintam e expressem suas emoções; 4) acompanhar como os filhos estão se informando, devido aos riscos da circulação de desinformações, fake news, procurando fontes confiáveis como UNICEF e OMS; 5) criar distrações bem-vindas, estimulando equilíbrio no uso do tempo em casa; 6) monitorar o próprio comportamento, sabendo que os pais também poderiam ficar ansiosos e influenciar negativamente o nível emocional dos filhos.

Outro ponto destacado pelo UNICEF é o risco direto de infecção de crianças, o que justificaria o fechamento das escolas como medida de controle dos altos riscos de contágio. A OMS (2020), por sua vez, também se preocupou em auxiliar pais e cuidadores na relação diária com crianças e adolescentes durante o isolamento social. Para isso, divulgou material e dicas sobre manter crianças e adolescentes com uma postura positiva diante da pandemia, estabelecer uma rotina diária flexível, mas constante, evitar TV, smartphones e tablets e praticar em família atividades como exercícios físicos, canto, dança, trabalhos domésticos, leitura. Tanto OMS (2020) quanto UNICEF (2020) reforçam também métodos de higiene pessoal para pessoas de todas as idades como forma de prevenção da doença.

\subsection{Agendamentos}

De acordo com a Teoria do Agendamento, ou Agenda Setting, aprofundada por Maxwell McCombs e Donald Shaw (1970), o agendamento pode ser focado na parte 


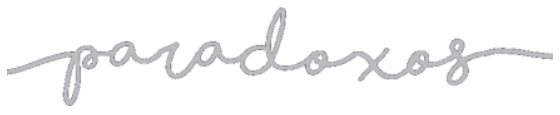

Covid-19 em revistas no Instagram: uma análise de conteúdo relacionada às orientações do UNICEF e da OMS

LEÃO, SERAFIM, NUNES, PEREIRA, 2020

discursiva, tratando um tema como um objeto (MCCOMBS, 2008). Esse objeto pode ser abordado de várias maneiras pelos meios de comunicação para sanar dúvidas, fornecer informações, influenciadas pelas necessidades do público (LIPPMANN, 1922). Assim, ocorreria um processo de construir formas de apresentar os conteúdos influenciando também como as pessoas enxergam o mundo e a sua própria existência, a partir da junção das imagens do mundo real, mas selecionadas e organizadas pelos meios de comunicação (BRUM, 2003; CASTELLS, 2006).

A teoria passou, então, por várias fases na tentativa de entender a influência dos meios de comunicação sobre o público. Inicialmente, por exemplo, havia a preocupação em torno de quem definia a agenda pública (anos 1970) ou a agenda da imprensa (anos 1980). O papel dessa teoria, no entanto, conforme indicam os autores, não se encerra em termos de qual o tema é colocado para discussão, mas abrange ainda a abordagem, a perspectiva do objeto discutido (MCCOMBS, 2007). De maneira geral, esse papel tem aproximação com alguns paradigmas da Comunicação como o enquadramento (framing), ao enfocar conteúdo e contexto, embora a proposta do Agenda Setting priorize expressamente o "conteúdo jornalístico manifesto" (MCCOMBS, 2007, p.48).

A "necessidade de orientação" (MCCOMBS, 2008, p.208) atuaria, por sua vez, como um marcador do efeito da Agenda Setting. Ou seja, à medida que essa necessidade aumenta, cresce o efeito do agendamento. A busca pela certeza das informações também é outro componente que ajuda a aumentar o efeito de agendamento, especialmente no caso em que há muita informação sendo divulgada e dúvida sobre a consistência do conteúdo (MCCOMBS, 2008).

Nesse sentido, Hohlfeldt (1997), que trata a perspectiva de Agenda Setting enquanto hipótese, justificando que dessa maneira permitiria um caminho mais alargado para experimentar e testar problemas de pesquisa, destaca alguns pressupostos relevantes com relação ao contato do público com grande quantidade de informação. O fluxo contínuo de informação é um deles, sobre contato do leitor com uma quantidade grande de informações ao longo do dia. Conteúdos jornalísticos poderiam contribuir para esse "processo de entropia" (HOHLFELDT, 1997, p.44). Em um cenário onde as pessoas dependem do tipo de informação que recebem para melhor compreender um tema relevante que interfere em suas rotinas e tomadas de decisões diárias, é possível que haja não só efeitos a curto prazo, mas uma híbrido momentâneo nas agendas individual, social e da mídia. 


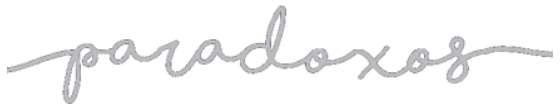

Covid-19 em revistas no Instagram: uma análise de conteúdo relacionada às orientações do UNICEF e da OMS

LEÃO, SERAFIM, NUNES, PEREIRA, 2020

Dessa maneira, decisões diárias do público podem depender do tipo de informação obtida, das perspectivas de especialistas e de dados de fontes institucionais, especialmente quando observamos um tema relevante e pouco conhecido. Nesse contexto, ressaltamos a relevância deste trabalho de análise das postagens de perfis da rede social Instagram, verificando o alinhamento com orientações do UNICEF e OMS sobre a pandemia de Covid-19 e isolamento social com crianças.

\section{Postagens e averiguações}

Através de uma pesquisa de caráter documental, foram selecionadas as postagens das revistas Crescer (@ revistacrescer $)^{5}$ e Pais \& Filhos (@paisefilhosoficial) ${ }^{6}$ no Instagram, entre 12 de março e 11 de abril de 2020. Foram observadas as postagens da galeria fixa principal, em que textos e aspectos imagéticos (fotos, gráficos ou vídeos) se ancoram na exposição de conteúdos. Não foram levados em consideração Stories, galeria de vídeos do IGTV ou Lives. Seguindo proposta metodológica composta por três passos principais, a presente análise consiste em: contagem geral das postagens no período e triagem (coleta do material), descrição dos dados (postagens relevantes) e categorização temática dos dados (temas predominantes) seguidas de uma avaliação dos conteúdos.

a. Coleta, categorização e descrição do material identificado

As postagens consideradas relevantes são as de caráter informativo, que visam contribuir para o esclarecimento da Covid-19, causada pelo novo Coronavírus, identificadas na galeria fixa principal $(f e e d)$ dos perfis das revistas. Foram identificadas um total de 150 postagens no perfil @ revistacrescer e 570 no @ paisefilhosoficial, na galeria fixa principal durante o período observado. Nesses grupos gerais de postagens, tanto havia conteúdos relacionados à Covid-19 quanto outros, como humor, cinema, gravidez, jogos, eventos, maternidade e paternidade, memes, celebridades, diversidade, e síndrome de down, representando um agendamento de temas variados.

\footnotetext{
${ }^{5}$ Disponível em: https://www.instagram.com/revistacrescer/. Acesso em: 16 de mai. de 2020.

${ }^{6}$ Disponível em: https://www.instagram.com/paisefilhosoficial/. Acesso em: 16 de mai. de 2020. 
Em seguida, observando esses grupos de postagens iniciais, foram separadas 77 postagens de @revistacrescer e 240 de @ paisefilhosoficial que abordavam o tema da Covid-19, incluindo conteúdos que buscam esclarecer sobre a pandemia e os que apenas o tangenciam, como abordagem humorística sobre riscos de contágio como através do espirro, memes, casos curiosos, repostagens de outros perfis ou campanhas ${ }^{7}$ motivacionais com imagem e texto utilizando hashtags.

Assim, quando buscamos nessas postagens que evidenciaram o tema da Covid-19 aquelas que se propunham a dizer algo além das abordagens tangenciais, foram identificadas 9 do perfil @ revistacrescer e 146, do @ paisefilhosoficial. Essas postagens buscavam contribuir com dados, dicas de como lidar com o momento da pandemia, participação de especialistas, vídeos didáticos com linguagem para pais, cuidadores e crianças, além de tabelas, infográficos ou prestação de serviço relacionado ao tema, como no combate às fake news. Não detalhamos todos na análise, pois havia repetição de temáticas, especialmente no caso de @paisefilhosoficial, mas agrupamos por pautas similares, com algumas postagens representativas.

b. Avaliação dos conteúdos selecionados

As hashtags mais presentes no perfil @ paisefilhosoficial entre as postagens observadas foram \#coronavirus e \#quarentena, enquanto @ revistacrescer fez uso dessas e da \#xocoronavirus.

Entre os principais pontos abordados em @paisefilhosoficial nas 146 postagens que buscavam esclarecer sobre a situação da Covid-19, estavam: atualização de casos de infecções no Brasil, como cuidar da educação, do lazer e da saúde das crianças durante a quarentena, sintomas da doença, formas de evitar o contágio, formas para as famílias lidarem com o estresse causado pelo isolamento social e como cuidar da produtividade no trabalho em casa. Houve repetição desses assuntos ao longo do período observado, indicando que são aspectos preocupantes no agendamento específico dessas pautas.

\footnotetext{
${ }^{7}$ Um exemplo de campanha, nesse período, foi a "Juntos é Possível” (@paisefilhosoficial), com postagens de palavras em cards, fotos ou partes de fotos que compõem o mosaico de uma imagem maior no feed, com a proposta de mostrar empatia no momento da pandemia, com hashtags como \#coronavirus e as frases "Estamos separados, mas nunca fomos tão próximos! Juntos é possível!".
} 
O perfil @ revistacrescer apresentou um número expressivamente menor, de 9 postagens específicas, sobre sintomas, formas de manter contato durante o isolamento social, combate ao contágio do novo Coronavírus, educação, alimentação e cuidados com as crianças.

Dessa forma, trazemos à tona algumas dessas postagens do agendamento específico dos perfis das revistas que buscaram ir além de uma abordagem tangencial ao tema da Covid-19. No perfil @ revistacrescer (12 de março), por exemplo, foi postada uma tabela diferenciando sintomas de resfriado, gripe e Covid-19, sendo parte de um "Especial Coronavírus", que o perfil já vinha divulgando em dias anteriores ao início do recorte temporal desta análise. No caso, a postagem parecia mostrar que ainda não estava claro para muitas pessoas o que diferenciava a Covid-19 de outras doenças similares. Além disso, mostrou no mesmo dia um caso de fake news de um áudio de um médico sobre tendência de crescimento dos casos de Covid-19 no Brasil. Nesse mesmo dia, @ revistapaisefilhos oficial também abordou diferenças entre infecção, epidemia e pandemia, além de falar sobre fake news sobre casos de infectados na Grande São Paulo. Essas diferenciações, embora pareçam triviais, são de grande relevância, pois ajudam a conscientizar sobre os riscos em um cenário de pandemia.

Quanto à questão do combate às fake news, um tema particularmente pontuado pelo UNICEF como relevante, o perfil @ paisefilhosoficial fez uma postagem especial (16 de março) com vídeo de Andressa Simonine, editora executiva explicando um novo serviço. A revista receberia dúvidas de conteúdos dos leitores através da caixa de mensagens no Instagram para checagem. O resultado poderia voltar como resposta direta ou gerar uma pauta para aprofundar o tema. Tanto no texto como no vídeo, constam explicações de que a medida visava combater as fake news e ao pânico diante de tantas informações naquele momento no Brasil, chamando a atenção dos seguidores/leitores para o filtro necessário ao receber e compartilhar conteúdos, a exemplo da falsa notícia sobre suspensão de aposentadoria de idosos no país por causa do novo Coronavírus (em 20 de março).

No mesmo dia em que lançou o serviço de checagem de fake news, @ paisefilhoos apresentou um vídeo de cerca de dois minutos, com reportagem sobre a importância dos pais abordarem o assunto do novo Coronavírus com as crianças e a necessidade de adaptações nesse diálogo, de acordo com as diferentes idades, além de que medidas de higiene como o ato de lavar as mãos ajudam a prevenir outras doenças, não só a Covid- 


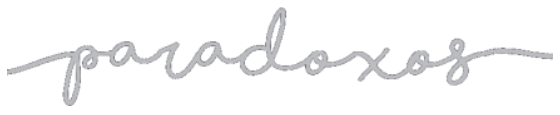

Covid-19 em revistas no Instagram: uma análise de conteúdo relacionada às orientações do UNICEF e da OMS

LEÃO, SERAFIM, NUNES, PEREIRA, 2020

19. Em outra postagem, apresentava um guia rápido com dicas para os pais conciliarem as obrigações do trabalho durante a quarentena e a orientação das atividades escolares em casa. Depois (20 de março), houve outro guia, dessa vez em PDF, elaborado e disponibilizado no Stories, sobre Coronavírus e formas de proteção da família.

Os colunistas de @ paisefilhosoficial também se apresentaram ativos na colaboração sobre conteúdos no período analisado. Especialmente na parte de Educação, as especialistas Taís Bento e Roberta Bento, também conhecidas por um perfil próprio no Instagram (@soseducacao), colaboraram com Lives e conteúdos para @ paisefilhosoficial, como um vídeo sobre "rotina saudável" (16 de março), com dicas sobre trabalhar em casa e como organizar as atividades com os filhos. No perfil @ revistacrescer, a colunista e pediatra Ana Maria Escobar apresentou recomendações quanto a questões de saúde, como sobre a necessidade de redobrar os cuidados com a higiene íntima de bebês e crianças, que ainda utilizavam fraldas e não sabem ou poderiam fazer a higiene sozinhas (24 de março).

Em@ @revistacrescer, a rotina educacional também é retomada na questão da Educação, focando no ensino online e em formas de aliviar o estresse do momento para pais e filhos. Postagem com declarações do diretor da Associação Brasileira de Escolas Particulares, Arthur Fonseca Filho, destaca a adoção do ensino online por algumas escolas (30 de março). A confecção de brinquedos foi uma forma apresentada para ocupar o tempo das crianças, estimular a criatividade e aproximar pais e filhos (26 de março). A revista indicou podcasts infantis para desenvolver a imaginação e ampliar o conhecimento (30 de março) e apresentou um infográfico com dicas sobre rotina educacional dos filhos em casa (7 de abril). Esses assuntos se relacionam com as orientações do UNICEF e da OMS no que diz respeito à rotina de aprendizagem e atividades em casa, configurando outro agendamento relevante.

Quanto ao lado emocional, algumas postagens de@paisefilhosoficial sobre como sobre lidar com a frustração das crianças em quarentena (17 de março) e sensação de impotência e vulnerabilidade (18 de março) estão alinhadas com a questão da empatia, destacada pelo UNICEF. Elas são especialmente relevante como agendamento em um momento de pandemia. Outras nessa linha são: como uma sobre manter o equilíbrio emocional dos pais na quarentena (24 de março) e os cuidados para comemorar o aniversário dos filhos diante de tantas tensões na quarentena (19 de março 


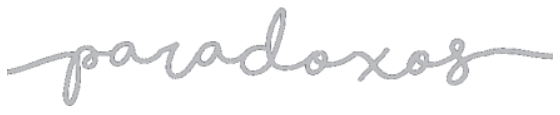

Covid-19 em revistas no Instagram: uma análise de conteúdo relacionada às orientações do UNICEF e da OMS

LEÃO, SERAFIM, NUNES, PEREIRA, 2020

e 7 de abril), além de meditação para toda a família na quarentena e formas alternativas de manter contato entre netos e avós ( 8 de abril). Fala-se também em emoções na depressão pós-parto durante o período da pandemia e a importância de uma rede de apoio ativa (7 de abril), pois, apesar de desafiador, "o isolamento social é uma recomendação da Organização Mundial da Saúde (OMS) e deve ser cumprido por todos" (@paisefilhosoficial, 2020).

Esses foram, então, alguns dos principais contextos de agendamento, com postagens de conteúdos específicos identificadas e quantificadas dentro da temática da Covid-19, trazidas à tona a partir da observação dos perfis das revistas na rede social Instagram.

\section{Considerações finais}

Diante de um tema de grande relevância, do qual pouco se sabia e pelo qual grande parte do público tinha interesse, as demandas por informações e orientações tendem a ser intensas (MCCOMBS, 2008; HOHLFELDT, 1997). Nesse cenário, veículos de comunicação tentam atender aos assuntos e necessidades do momento (CASTELLS, 2006). Então, formas de prevenção e construções explicativas da mídia tentam suprir essa lacuna, como um grande quebra-cabeças, a exemplo das postagens das revistas com uso de elementos como ilustrações, vídeos e textos tentando envolver vários aspecto no Instagram, transparecendo o agendamento do objeto: a Covid-19. A agenda da mídia e a agenda pública tendem, portanto, a compartilhar preocupações muito próximas nesse cenário.

Houve conteúdos diversos nos perfis@ @aisefilhosoficial e @ revistacrescer no período analisado. É interessante observar que, o perfil @ revistacrescer, que apresentava maior número de seguidores na rede social Instagram do que o perfil @paisefilhos, apresentou o menor número de postagens relevantes sobre Covid-19.

No tocante ao perfil @ paisefilhos, é válido ressaltar que este se mostrou preocupado em utilizar o espaço no Instagram como canal informativo, e não apenas entreter, com postagens diversas sobre a Covid-19, além da proposta de um serviço para seus leitores de verificação de notícias e combate ao fake news, evidenciando uma característica própria do DNA das revistas de fazer aproximações com os leitores. Percebe-se também que o foco não precisa estar essencialmente na parte lúdica, de 


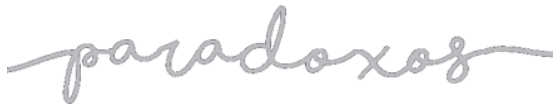

Covid-19 em revistas no Instagram: uma análise de conteúdo relacionada às orientações do UNICEF e da OMS

LEÃO, SERAFIM, NUNES, PEREIRA, 2020

entretenimento na adaptação de diálogo com os mais jovens. Portanto, quando revistas como as analisadas, com foco em famílias e atuando em uma rede social onde reúnem um número elevado de seguidores, ignoram aspectos de questões relevantes como saúde pública ou não exploram em suas postagens a temática por uma proposta informativa, podem estar perdendo a oportunidade colaborar com os leitores na busca por orientação, fugindo da responsabilidade social de usar esse espaço de forma relevante.

Por fim, compreendemos que apesaar de medidas difíceis de serem aplicadas nesse contexto, como o isolamento social, é possível perceber que "a sociedade em rede é uma sociedade hipersocial, não uma sociedade de isolamento" (CASTELLS, 2006, p.23), é uma sociedade que se comunica e se interliga via cabos e redes visando ações conjuntas que beneficiem a coletividade.

\section{Referências bibliográficas}

BENETTI, Marcia. Revista e jornalismo: conceitos e particularidades. In: TAVARES, Frederico de Mello B.; SCHWAAB, Reges (Orgs.). A revista e seu jornalismo: Porto Alegre: Penso, 2013.

BRUM, Juliana de. A Hipótese do Agenda Setting: Estudos e Perspectivas. Revista Razón y Palabra, no 35, outubro-novembro de 2003. Disponível em: <http://www.razonypalabra.org.mx/anteriores/n35/jbrum.html >. Acesso em: 29 de abr. de 2020.

CASTELLS, Manuel. A Sociedade em Rede: do Conhecimento à Política. In: CASTELLS, Manuel; CARDOSO, Gustavo (Orgs.). A Sociedade em Rede: Do Conhecimento à Acção Política. : Imprensa Nacional - Casa da Moeda, 2006, p. 17-30. Disponível em: <https://egov.ufsc.br/portal/sites/default/files/a_sociedade_em_rede_do_conhecimento_a_acao_politica.pdf>. Acesso em: 22 de abr. de 2020.

DA SILVA JUNIOR, José Afonso; PROCOPIO, Pedro Paulo; DOS SANTOS MELO, Mônica. Um Panorama da Teoria do Agendamento, 35 anos depois de sua formulação. Intercom - Revista Brasileira de Ciências da Comunicação. 2008, 31(2), 205-221. Disponível em: 〈https://www.redalyc.org/articulo.oa?id=69830990011〉. Acesso em: 5 de abr. de 2020.

DOURADO, Tatiana Maria Silva Galvão. Revistas em formatos digitais: modelos e novas práticas jornalísticas. Dissertação (Mestrado) - Faculdade de Comunicação, Universidade Federal da Bahia, Salvador, 2013. Disponível em: <https://repositorio.ufba.br/ri/bitstream/ri/14009/1/Tatiana\%20Maria\%20Dourado.pdf $>$. Acesso em: 29 de abril de 2020. 


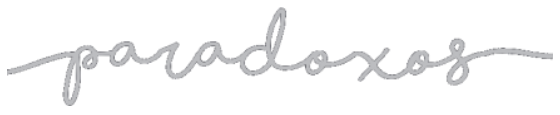

Covid-19 em revistas no Instagram: uma análise de conteúdo relacionada às orientações do UNICEF e da OMS

LEÃO, SERAFIM, NUNES, PEREIRA, 2020

FRANCHI, Francesco. Designing News. Gestalten: Berlin, 2013

KLEIN, Gisiela Hasse; GUIDI NETO, Pedro; TEZZA, Rafael. Big Data e mídias sociais: monitoramento das redes como ferramenta de gestão. Saude soc., São Paulo, v. 26, n. 1, p. 208-217, Mar. 2017. Disponível em:

$<$ http://www.scielo.br/scielo.php?script=sci arttext\&pid=S0104$12902017000100208 \& \operatorname{lng}=\mathrm{en} \& n \mathrm{~nm}=\mathrm{iso}>$. Acessado em 10 de mai. de 2020.

HOHLFELDT, Antonio. Os estudos sobre a hipótese de agendamento. Revista Famecos, Porto Alegre, n $^{\circ}$, novembro, 1997

LIPPMAN, Walter. Opinião pública. Petrópolis: Vozes, 2008.

LEÃO, Callenciane F. Recursos de storytelling jornalístico em dispositivos móveis: a revista Época para tablet. Dissertação (Mestrado) - Faculdade de Biblioteconomia e Comunicação, Universidade Federal do Rio Grande do Sul, Porto Alegre, 2015. Disponível em: $<$ https://www.ufrgs.br/jordi/wp-content/uploads/2016/05/Recursos-de-storytellingjornal\%C3\%ADstico-em-dispositivos-m\%C3\%B3veis-a-revista-\%C3\%89poca-paratablet.pdf>. Acesso em 17 abr. 2020.

MCCOMBS, Maxwell; SHAW, Donald L. The Agenda-Setting Function of Mass Media. The Public Opinion Quarterly. Vol. 36, No 2. Summer, 1972. Disponível em: <https://www.jstor.org/stable/2747787>. Acesso em: 20 de abr. de 2020.

MCCOMBS, Maxwell; VALENZUELA, Sebastián. The Agenda-Setting Theory. Cuadernos de Información, Santiago, Chile, núm. 20, pp. 44-50, julho, 2007. Disponível em:

<http://www.redalyc.org/articulo.oa?id=97120369004>. Acesso em: 15 de abr. de 2020.

OLIVEIRA, Fabrício Marques de. Cápsulas do tempo: a revista em contexto digital. In: Anais do $9^{\circ}$ Encontro Nacional de Pesquisadores em Jornalismo (SBPJor). 2011, Rio de Janeiro. Disponível em:

<http://www.academia.edu/11379108/C\%C3\%A1psulas_do_tempo_a_revista_em_c ontexto_digital>. Acesso em: 17 abr. 2020.

OMS. Consejos para el público sobre la enfermedad por coronavirus (COVID-19): crianza saludable. 2020. Disponível em:

<https://www.paho.org/es/documentos/consejos-para-publico-sobre-enfermedad-porcoronavirus-covid-19-crianza-saludable>. Acesso em: 17 de abr. de 2020

PAULINO, Rita. Conteúdo digital interativo para tablets-ipad: uma forma híbrida de conteúdo digital. In: PAULINO, Rita; RODRIGUES, Rodrigues (Orgs.) Jornalismo para tablets: pesquisa e prática. Florianópolis: Insular, 2013.

PEREIRA, Germana da Cruz. As representações do gênero feminino no seriado televisivo A grande família: uma análise crítica do discurso imagético-verbal. 2014. 155f. - Tese (Doutorado) - Universidade Federal do Ceará, Departamento de Letras Vernáculas, Programa de Pós-graduação em Linguística, Fortaleza (CE), 2014. 


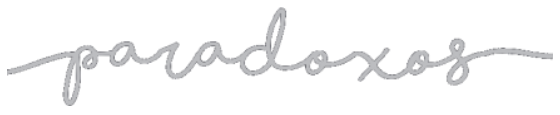

Covid-19 em revistas no Instagram: uma análise de conteúdo relacionada às orientações do UNICEF e da OMS

LEÃO, SERAFIM, NUNES, PEREIRA, 2020

RECUERO, R. Redes Sociais na Internet. Porto Alegre: Ed. Sulina, 2009.

RECUERO, R. Discutindo Análise de Conteúdo como Método: O

\#DiadaConsciênciaNegra no Twitter. In: Cadernos de Estudos Linguísticos (56.2), p. 289-309, julho/dezembro, 2014, Unicamp/SP.

SCALZO, Marília. Jornalismo de revista. São Paulo: Contexto, 2011.

SELTZER, E.K. et al. The content of social media's shared images about Ebola: a retrospective study. In Public Health (129.9) . pp. 1273-1277, setembro, 2015. Reino Unido. Disponível em:

$<$ https://www.sciencedirect.com/science/article/abs/pii/S0033350615002851?via\%3Dih $\underline{\mathrm{ub}}>$. Acesso em: 19 de mai. de 2020.

TAVARES, Frederico de Mello B.; SCHWAAB, Reges (Orgs.). A revista e seu jornalismo. Porto Alegre: Penso, 2013.

UNICEF. 6 Ways parents can support their kids through the coronavirus disease (COVID19) outbreak. 2020. Disponível em: <https://www.unicef.org/coronavirus/6-ways-parentscan-support-their-kids-through-coronavirus-covid-19>. Acesso em 20 de abril de 2020.

UNICEF. How to talk to your child about coronavirus disease 2019 (COVID-19). 2020. Disponível em: <https://www.unicef.org/coronavirus/how-talk-your-child-aboutcoronavirus-covid-19>. Acesso em 20 de abril de 2020.

UNICEF. Coronavirus disease (COVID-19): What parents should know. 2020.

Disponível em: <https://www.unicef.org/stories/novel-coronavirus-outbreak-whatparents-should-know>. Acesso em 21 de abril de 2020.

UNICEF; WWH; IFRC. Key Messages and Actions for COVID-19 Prevention and Control in Schools. 2020. Disponível em: <https://www.who.int/docs/defaultsource/coronaviruse/key-messages-and-actions-for-covid-19-prevention-and-control-inschools-march-2020.pdf?sfvrsn=baf81d52_4>. Acesso em 20 de março de 2020.

VOGEL, Daisi. Revista e contemporaneidade: imagens, montagens e suas anacronias. In: TAVARES, Frederico de Mello B.; SCHWAAB, Reges (Orgs.). A revista e seu jornalismo. Porto Alegre: Penso, 2013.

YUXIN Zhao et al. Chinese Public's Attention to the COVID-19 Epidemic on Social Media: Observational Descriptive Study. In J Med Internet. Res 2020. 4 de maio; 22(5):e18825. Disponível em: 〈https://www.jmir.org/2020/5/e18825/>. Acesso em: 10 de mai. de 2020. 